\title{
Surfactant induced reservoir wettability alteration: Recent theoretical and experimental advances in enhanced oil recovery
}

\author{
Wang Yefei ${ }^{1,2 *}$, Xu Huaimin ${ }^{1}$, Yu Weizhao ${ }^{2}$, Bai Baojun ${ }^{3}$, Song Xinwang ${ }^{4}$ and \\ Zhang Jichao ${ }^{4}$ \\ ${ }^{1}$ College of Geosciences, China University of Petroleum, Beijing 102249, China \\ ${ }^{2}$ College of Petroleum Engineering, China University of Petroleum, Qingdao, Shandong 266555, China \\ ${ }^{3}$ Department of Geological Science \& Engineering, Missouri University of Science \& Technology, Rolla, 65409-0410, USA \\ ${ }^{4}$ Geological and Scientific Research Institute, SINOPEC Shengli Oilfield Company, Dongying, Shandong 257015, China \\ (C) China University of Petroleum (Beijing) and Springer-Verlag Berlin Heidelberg 2011
}

\begin{abstract}
Reservoir wettability plays an important role in various oil recovery processes. The origin and evolution of reservoir wettability were critically reviewed to better understand the complexity of wettability due to interactions in crude oil-brine-rock system, with introduction of different wetting states and their influence on fluid distribution in pore spaces. The effect of wettability on oil recovery of waterflooding was then summarized from past and recent research to emphasize the importance of wettability in oil displacement by brine. The mechanism of wettability alteration by different surfactants in both carbonate and sandstone reservoirs was analyzed, concerning their distinct surface chemistry, and different interaction patterns of surfactants with components on rock surface. Other concerns such as the combined effect of wettability alteration and interfacial tension (IFT) reduction on the imbibition process was also taken into account. Generally, surfactant induced wettability alteration for enhanced oil recovery is still in the stage of laboratory investigation. The successful application of this technique relies on a comprehensive survey of target reservoir conditions, and could be expected especially in low permeability fractured reservoirs and forced imbibition process.
\end{abstract}

Key words: Wettability alteration, reservoir, enhanced oil recovery (EOR), surfactant

\section{Introduction}

Wettability is defined as the tendency of one fluid to spread on, or adhere to, a solid surface in the presence of other immiscible fluids. This is a major factor controlling the location, flow, and distribution of fluids in a reservoir. Many investigations of wettability and its effects on oil recovery have come to the conclusion that there is a favorable reservoir wettability for operators to recover maximum crude oil from a given subterranean reservoir (Morrow et al, 1984; Anderson, 1987; Morrow, 1990; Rao et al, 1992; Jadhunandan and Morrow, 1995; Zhou et al, 2000; Dwarakanath et al, 2002; Hatiboglu and Babadagli, 2006; Johannesen and Graue, 2007a; 2007b). So recovery of oil by altering reservoir wettability has been paid more attention and intensively studied for the past 50 years, especially for fractured reservoirs. And spontaneous imbibition controlled by wettability has been recognized as a significant mechanism

* Corresponding author. email: wangyf@upc.edu.cn Received January 8, 2011 for oil recovery (Jadhunandan and Morrow, 1991; Morrow and Mason, 2001; Hirasaki and Zhang, 2004; Ayirala and Rao, 2006; Ayirala et al, 2006; Xu et al, 2006; Zhang et al, 2007).

\section{Reservoir wettability and its evolution}

For many years, it has been common petroleumengineering practice to assume that oil reservoirs were strongly water-wet. Because most reservoir rock is highly siliceous and oil reservoirs evolve by oil migrating into initially brine-occupied pore space, it was thought that the rock surface maintains a strong affinity for water even in the presence of oil (Morrow, 1991). In 1973, however, Salathiel established that reservoirs with mixed wettability display low residual oil (that is, oil trapped as isolated globules) and consequently high displacement efficiency, as gauged by the ratio of oil recovered after waterflooding to the original oil in place (Morrow, 1991). Actually, wettability of reservoirs covers a broad spectrum from strongly water-wet to oil-wet, many of reservoirs are verified to be non-water-wet and oilwet states are not rare. 
Wettability in porous media is generally classified as either homogeneous or heterogeneous. For the homogeneous case, the entire rock surface has a uniform molecular affinity for either water or oil. Conversely, heterogeneous wettability indicates distinct surface regions that exhibit different affinities for oil or water.

There are several quantitative methods to measure the homogeneous wettability of reservoir porous media, such as USBM (Anderson, 1986a) and Amott methods (Amott, 1959), as well as some qualitative methods such as imbibition and flotation methods (Anderson, 1986b). Three broad classifications of homogeneous wetting exist: strongly water-wet, strongly oil-wet, and intermediate-wet. If smooth representative rock surfaces can be prepared, then contact angles for oil on water-wet surfaces, measured through the water phase, are near zero. While for oil-wet surfaces, they are near $180^{\circ}$. In the case of intermediate-wetting the rock has neither a strong affinity for water nor oil and contact angles range roughly from $45^{\circ}$ to $135^{\circ}$ (Craig, 1971).

Treiber and Owens (1972) used the water advancing contact angle to examine the wettability of 55 oil reservoirs with contact angle as criterion of wettability. Contact angles (measured through the water) from 0 to $75^{\circ}$ were deemed water-wet, from $75^{\circ}$ to $105^{\circ}$ were intermediate wet, and from $105^{\circ}$ to $180^{\circ}$ were oil-wet. As summarized in Table 1, 37 of the reservoirs tested were classified as oil-wet, 3 were of intermediate wettability, and 15 were water-wet. Most of the oil-wet reservoirs were mildly oil-wet, with a contact angle between $120^{\circ}$ and $140^{\circ}$. Of the carbonate reservoirs concerned, $8 \%$ were water-wet, $8 \%$ were intermediate, and $84 \%$ were oil-wet. Most of the carbonate reservoirs were from the west Texas area, so there is a geographical bias in the data.

Table 1 Distribution of reservoir wettabilities based on contact angle (after Treiber and Owens, 1972)

\begin{tabular}{ccccc}
\hline & $\begin{array}{c}\text { Contact angle } \\
\text { (degrees) }\end{array}$ & $\begin{array}{c}\text { Silicate } \\
\text { reservoirs }\end{array}$ & $\begin{array}{c}\text { Carbonate } \\
\text { reservoirs }\end{array}$ & $\begin{array}{c}\text { Total } \\
\text { reservoirs }\end{array}$ \\
\hline $\begin{array}{c}\text { Water-wet } \\
\text { Intermediate } \\
\text { wet } \\
\text { Oil-wet }\end{array}$ & $0-75$ & 13 & 2 & 15 \\
\hline Total & $75-105$ & 2 & 1 & 3 \\
\hline
\end{tabular}

Contact-angle measurements made by Chilingar and Yen suggest that most carbonate reservoirs range from intermediate-wet to oil-wet (Chilingar and Yen, 1993). They measured the wettability of 161 limestone, dolomitic limestone, calcareous dolomite, and dolomite cores. The cores tested covered many oil producing areas all over the world. Table 2 shows the distribution of wettabilities with $80 \%$ of the reservoirs either oil-wet or strongly oil-wet. It should be noted that the range of contact angles considered to be intermediate-wet is smaller than the range given in Table 1, which demonstrates the variation from paper to paper of the selected cutoff angles between the different wetting states.
Table 2 Distribution of carbonate reservoir wettabilities (after Chilingar and Yen, 1993)

\begin{tabular}{ccc}
\hline & $\begin{array}{c}\text { Contact angle } \\
\text { (degrees) }\end{array}$ & Percent of reservoirs \\
\hline Water-wet & $0-80$ & 8 \\
Intermediate wet & $80-100$ & 12 \\
Oil-wet & $100-160$ & 65 \\
Strong oil-wet & $160-180$ & 15 \\
\hline
\end{tabular}

During the formation of reservoirs, the original strong water-wetness state of most reservoir minerals can be affected or altered by oil composition, pressure, temperature, mineral surface, and brine chemistry, including ionic composition and $\mathrm{pH}$ (Anderson, 1986a). The adsorption of polar compounds and/or the deposition of organic matter that was originally in crude oil are believed to be an important factor responsible for wettability alteration. These compounds contain both polar and hydrocarbon moieties, and the polar end adsorbs on the rock surface, exposing the hydrocarbon end rendering the surface to be more oil-wet. Experiments have shown that some of these natural surfactants are sufficiently soluble in water to adsorb onto the rock surface after passing through a thin layer of water. Some research has demonstrated that some polar compounds affected the wettability of sandstone and carbonate surfaces in different ways, which resulted in the fact that a majority of carbonate reservoirs tested were oilwet, while many of the sandstone reservoirs were water-wet (Lowe et al, 1973; Morrow et al, 1973).

Smith et al (1989) proved that the acidic and basic crude oil components isolated by ion-exchange chromatography greatly reduced the rate of spontaneous brine imbibition by Berea sandstone, which indicated that these components have a strong effect on rock wettability. Xie et al (2010) also confirmed that the acid number of the crude oil was a key factor in changing the wettability of volcanic reservoir rocks. Neutral crude oil components had a minimal effect on rock wettability. Spectrophotometric measurements showed that crude oil, its acidic and basic components contained aromatic species that were adsorbed by Berea sandstone in the presence of a brine phase. Aromatic species in the neutral crude oil component were not adsorbed under these conditions. Since both acidic and basic crude oil components altered wettability, indicating that Berea sandstone does not exhibit an exclusively acidic or basic character with respect to its interactions with crude oil. Both acidic and basic crude oil components must be considered when predicting wetting tendencies in sandstones. Besides the discrimination of wettability alteration components in crude oil by their acidic/ basic and aromatic properties, the components separated from crude oil by solubility, especially asphaltenes and resins are also crucial for wettability study. Yan (1998b) established the correlation between wettability index and asphaltene adsorption to show the increase in the index with increasing amount of asphaltene adsorption. And the influence of anions, such as $\mathrm{Na}^{+}, \mathrm{Ca}^{2+}$, and $\mathrm{Al}^{3+}$, on adsorption of asphaltenes and 
wettability index was increased with the increase of valency (Yan, 1998a).

Buckley et al (1998) investigated the mechanisms of wetting alteration by crude oils and identified four main categories of crude oil/brine/rock interactions illustrated in Fig. 1, which include:

a) Polar interactions that predominate in the absence of

(a) Typical crude oil components with polar functionality
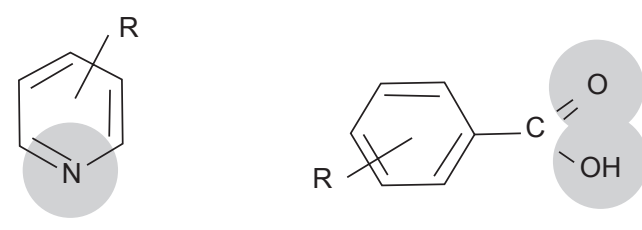

(c) Acid/base interactions

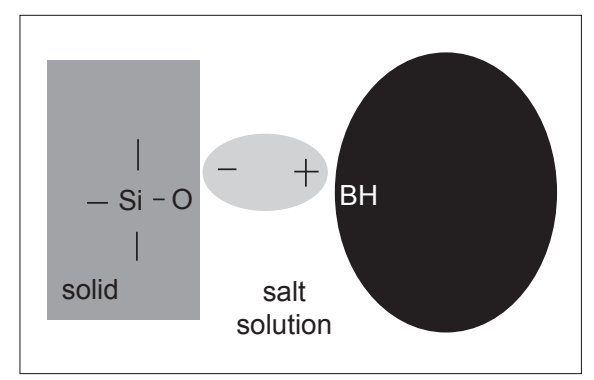

Fig. 1 Mechanisms of interaction between crude oil components and solid surfaces (after Buckley et al, 1998)

As to heterogeneous wettability, also called fractional, Dalmatian, speckled or spotted wettability, was first proposed by Brown and Fatt (1956). Robin et al (1995) used cryoscanning electron microscopy to confirm the existence of heterogeneous wettability on the pore scale in actual reservoir media. In heterogeneous wettability, crude oil components are strongly adsorbed in certain areas of rocks, which results in the situation that a portion of the rock is strongly oil-wet, while the rest is strongly water-wet (Morrow, 1991). It should be noted that this is conceptually different from intermediate wettability, which assumes that all portions of the rock surface have a slight but equal preference to being wetted by water or oil.

Mixed wettability was first introduced as a special type of heterogeneous wettability by Salathiel (1973), in which the oil-wet surfaces form continuous paths through the larger pores, while the smaller pores remain water-wet and contain no oil. The fact that all of the oil in a mixed-wettability core is located in the larger oil-wet pores causes a smaller but finite oil permeability to exist down to very low oil saturations. This in turn permits the drainage of oil during a waterflood to continue until very low oil saturations are reached (see Fig. 2). water film between oil and solid;

b) Surface precipitation, dependent mainly on crude oil solvent properties with respect to the asphaltenes;

c) Acid/base interactions that control surface charge at oil/ water and solid/water interfaces;

d) Ion binding or specific interactions between charged sites and higher valency ions.

(b) Surface precipitation

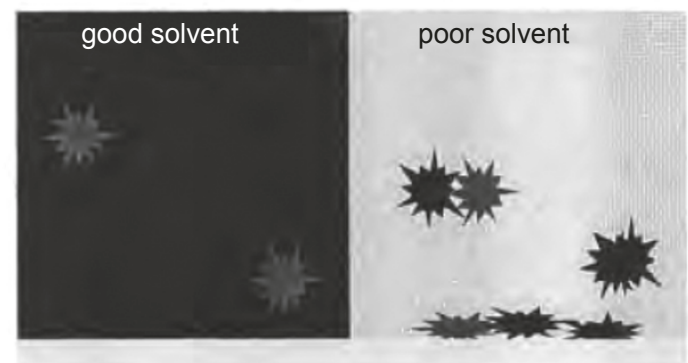

(d) lon-binding

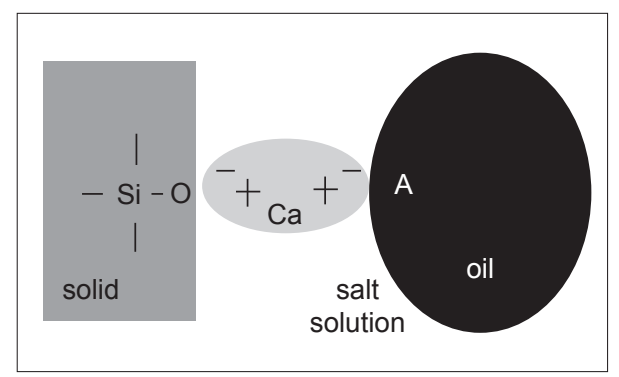

The main distinction between mixed and fractional wettability is that the latter implies neither specific locations for the oilwet surfaces nor continuous oil-wet paths.

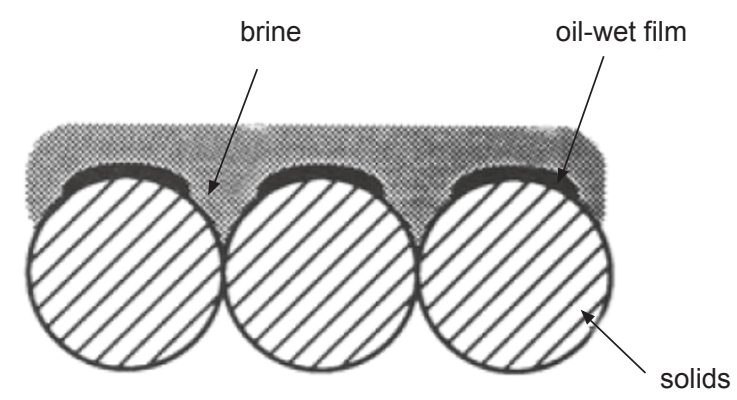

Fig. 2 Distribution of oil and brine in mix wetting cores (after Salathiel, 1973)

Salathiel (1973) visualized the generation of mixed wettability in the following manner. When oil initially invaded an originally water-wet reservoir, it displaced water from the larger pores, while the smaller pores remained 
water-filled because of capillary forces. A mixed-wettability condition occurred if the oil deposited a layer of oil-wet organic material only on those rock surfaces that were in direct contact with the oil but not on the brine-covered surfaces. Oil-wet deposits would not be formed in the small water-filled pores, allowing them to remain water-wet. The question that Salathiel did not address was how the oil first came into direct contact with the rock. As the oil moves into the larger pores, a thin layer of interstitial water remains on the pore walls, preventing oil from contacting the rock surface. Under certain conditions, however, the water film separating the crude and the mineral surface can rupture. Hall et al (1983) and Melrose (1982) developed a theoretical model for the stability of these thin water films, showing that the water films become thinner and thinner as more oil enters the rock. The water film is stabilized by electrostatic forces arising from the electrical double layers at the oil/water and water/rock interfaces. As the water film thickness is further reduced, a critical thickness is reached where the water films in larger pores become unstable. Subsequently the films rupture and are displaced, allowing oil to contact the rock.

Kovscek et al (1993) further investigated the development of mixed wettability at pore level in oil reservoirs. They found that a delicate interplay between pore shape and thinfilm chemistry and physics could predict mixed wettability in porous rocks. The presence of asphaltenes in the oil phase was indispensable for the generation of mixed wettability. In fact, their studies suggested that asphaltenes played a greater role in determining the evolution of mixed wettability than the underlying mineralogy of the rock. In a distribution of starshaped pores, the largest pores are prevented from becoming mixed-oil-wet, because their pore walls are protected by thick continuous water films. These films prohibit asphaltene adsorption and subsequent alteration in the wettability state of the pore surface. Conversely, ultrathin molecular films form on the walls of intermediate-sized star-shaped pores during pristine drainage, which permits irreversible asphaltene adsorption, and subsequently these pores became mixed-oilwet. The smallest pores which are never entered by oil remain water-wet (see Fig. 3).

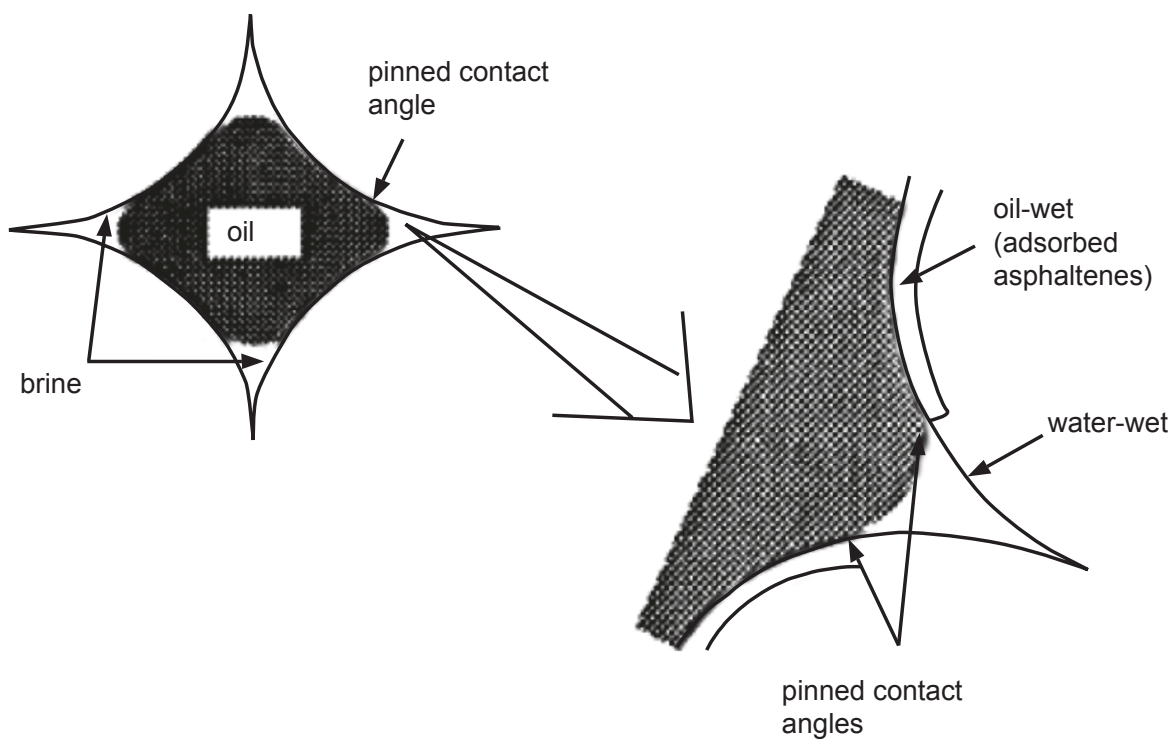

Fig. 3 Schematic of a mixed-oil-wet pore illustrating the location of asphaltene deposition and the coexistence of oil-wet and water-wet regions within a single pore (after Kovscek et al, 1993)

Remaining oil saturation, the long period of oil production, and high-efficiency waterflood of mixedwettability porous media are attributed to the formation of oil lenses or rivulets which span the corners of pores in addition to oil films adhering to pore walls. Oil drainage is slow due to large hydrodynamic resistances. With star-shaped pores these lenses or rivulets reside in pores of intermediate size. The notion of contact angle-pinning allows development of the bridging oil lenses (see Fig. 4).

Generally, the existence of complex wettability scenarios including homogeneous and heterogeneous wettability, fractional and mixed wettability has been accepted. And such intricate situations originate from complex interactions among crude oil, brine, and rock, covering diverse reservoirs. Understanding the precise wettability conditions for a specific reservoir is either the goal of wettability characterization or the basis of enhanced oil recovery technology by wettability alteration. So the research on wettability characterization and its effect on oil recover by various methods are still under investigation in petroleum science.

\section{Effect of reservoir wettability on recovery of oil}

Determination of the effect of reservoir wettability on oil recovery is a long-standing problem in reservoir engineering, and has been paid much attention in recent year (Kennedy et al, 1955; Amott, 1959; Taber, 1980; Morrow et al, 1984; Anderson, 1987; Morrow, 1990; Chen et al, 2009; Liu et al, 2009; Song et al, 2009b). Oil recovery during waterflooding is closely related to wettability, pore geometry, fluid distribution, saturation, saturation history, and oil/water viscosity ratio. Wettability affects waterflooding by controlling the flow and spatial distribution of fluids in porous media. Early examples 


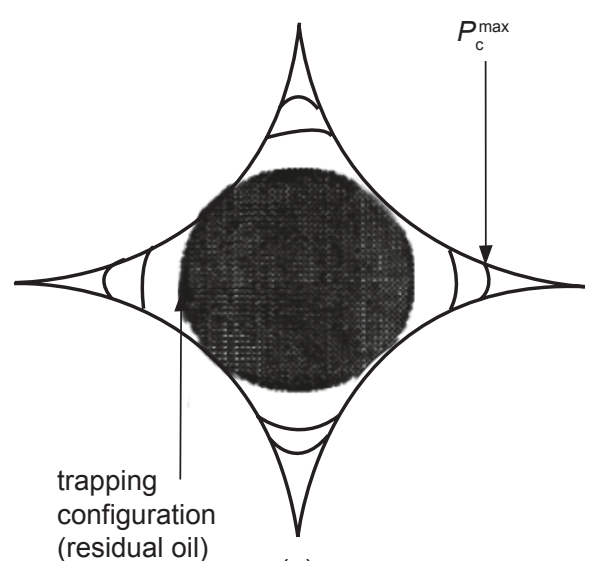

(a)

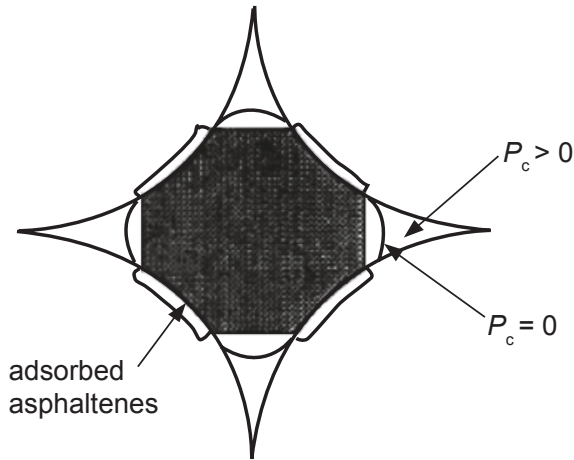

(b)

Fig. 4 Imbibition processes in water-wet (a) and mixed-oil-wet (b) pores during forced imbibition (after Kovscek et al, 1993)

of laboratory waterflood show oil recovery decreasing with decreasing water-wetness. This is consistent with the intuitive notion that strong wetting preference of the rock for water and associated strong capillary imbibition forces give the most efficient oil displacement. However, an increasing number of examples of improved recovery with shift from strongly water-wet conditions are being reported for weakly water-wet or intermediate wetting conditions, particularly for crude oil/ brine/rock (COBR) systems. These results generally involve displacement of crude oils or refined oils from cores in which organic films have been deposited from crude oil. Fig. 5 shows averaged results for an extensive COBR data set. In preparation of these samples, it was found that increased

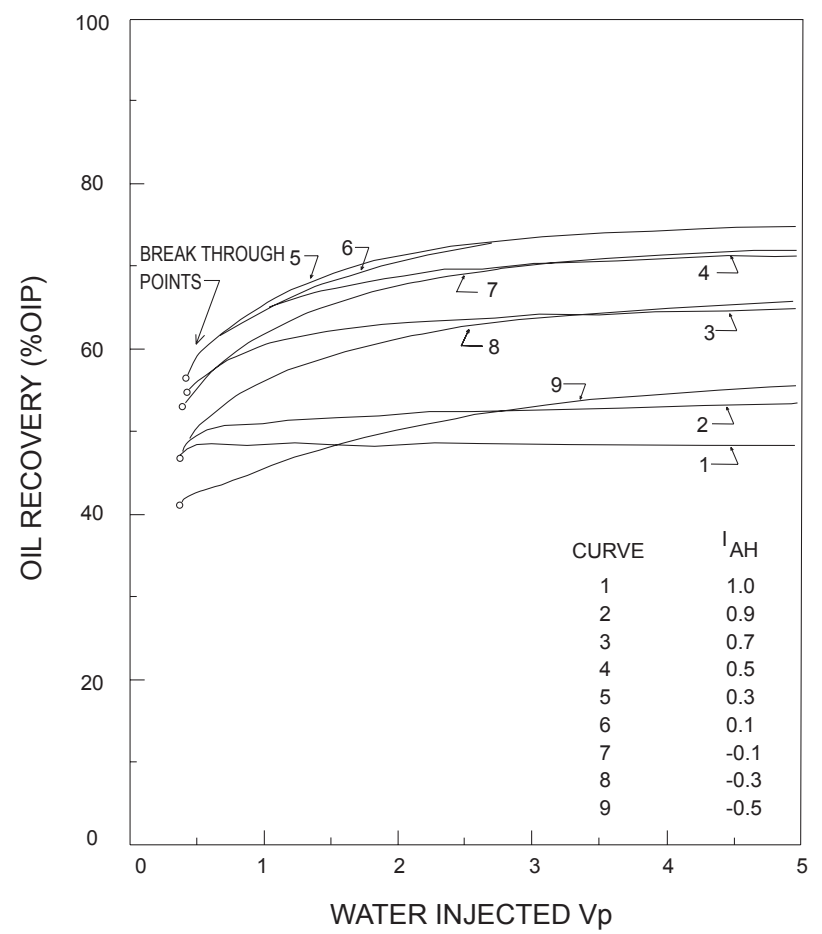

Fig. 5 Oil recovery vs. brine injected for COBR systems with AmottHarvey wettability index ranging from 1.0 to -0.5 (after Morrow, 1990) aging temperature, decreased water saturation, and to a lesser extent, increased aging time, all tended to make the cores less water-wet. Recovery is seen to pass through a maximum when Amott-Harvey wettability index $\left(\mathrm{I}_{\mathrm{AH}}\right)$ is close to zero(indicating intermediate wetness).

Fig. 6 shows the trend of ultimate oil recovery after waterflooding against wettability (Kennedy et al, 1955). The sessile-drop ratio, which is the height of an oil drop placed on a smooth silica surface immersed in brine divided by the diameter of the drop, was used to measure the wettability. The waterflooding experiments used an artificial core of chemically consolidated sand, brine, and East Texas crude oil. Different surfactants in the fluids were used to vary the wettability, while maintaining a constant interfacial tension (IFT). The maximum recovery (and minimum true residual saturation) occurred at a slightly oil-wet condition. As the wettability varied, however, the change in true residual oil saturation was small, about $5 \%$.

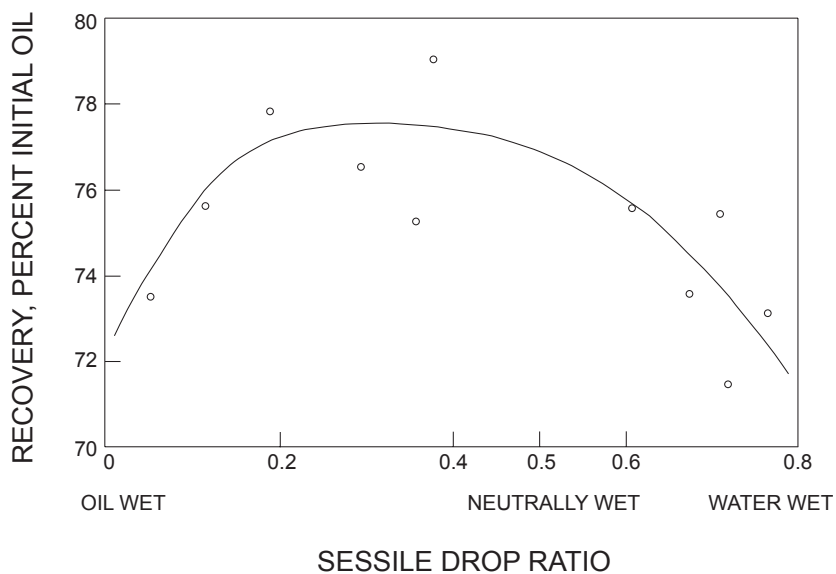

Fig. 6 Effect of wettability on ultimate oil recovery, synthetic silica core, East Texas crude oil, and surfactant-treated brine (after Kennedy et al, 1955)

More than 50 slow-rate waterfloods were performed for a wide variety of COBR systems with crude oil, brine 
composition, aging time and flooding rate as the main variables (Jadhunandan and Morrow, 1995). In developing a general correlation between oil recovery and wettability, data that showed obvious end effects and viscous fingering (discussed in the effect of flood rate on oil recovery section) were not used. Fig. 7(a) plots oil recovery at breakthrough, $3 \mathrm{PV}$, and $20 \mathrm{PV}$ injected vs. wettability index, $\mathrm{I}_{\mathrm{w}-\mathrm{o}}$. The data show a maximum in recovery at wettability close to, but on the water-wet side of, neutral $\left(\mathrm{I}_{\mathrm{w}-\mathrm{o}} \approx 0.2\right)$, which becomes

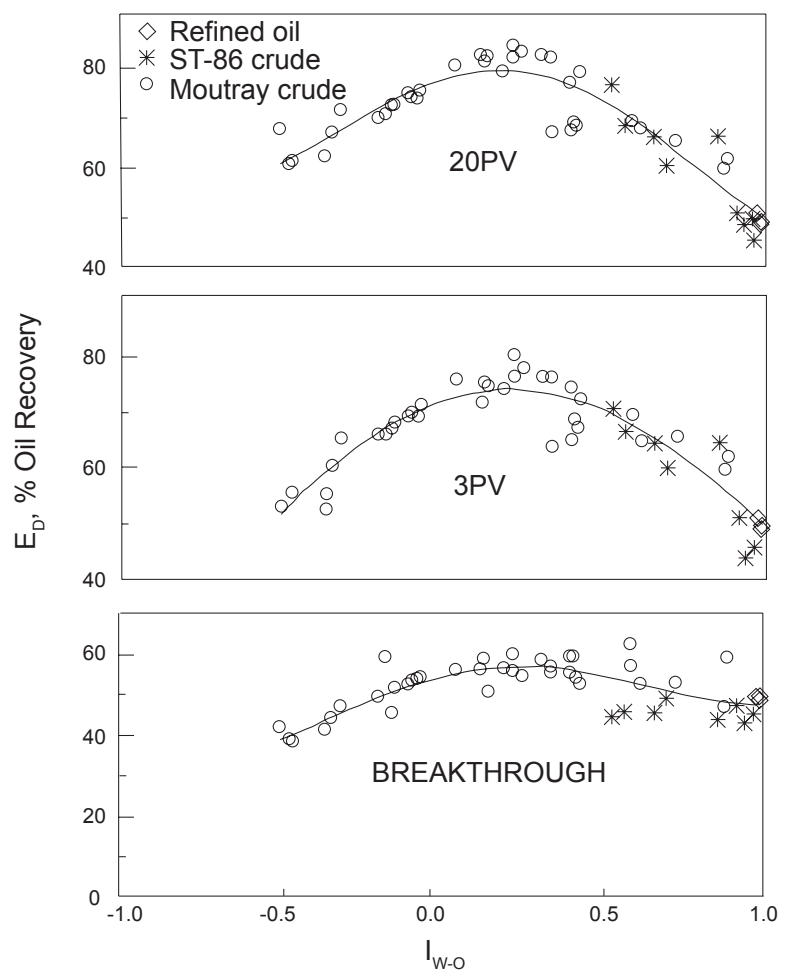

(a) increasingly definitive with continued flooding. If systems that showed little or no co-production of oil and water were omitted from the curve-fitting routine, it can be seen that an improved correlation would be obtained, with the maximum in recovery becoming several percent higher. Fig. 7(b) shows corresponding results for residual oil saturation. With respect to previous work on the effect of wettability on oil recovery, Amott's results provide the closest qualitative similarity to these results (Amott, 1959).
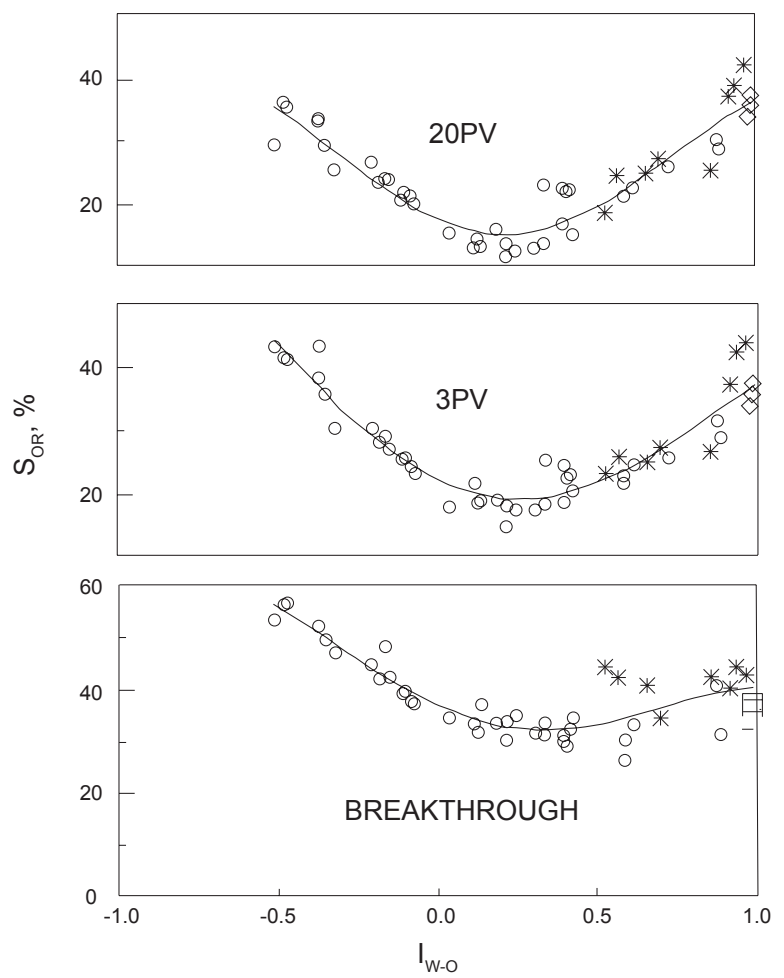

(b)

Fig. 7 Oil recovery (a) and residual oil (b) vs. $I_{w-o}$ (after Amott, 1959)

The variation in recovery with wettability is determined by complex changes in pore-level displacement mechanisms that may well involve small-scale heterogeneities. In strongly water-wet Berea sandstone, refined oil has been shown to be trapped through disconnection of oil at pore throats (snap-off) to form blobs that largely fill the pore bodies (Chatzis et al, 1983). Trapping of crude oil have also investigated in 2D pore networks - crude-oil/brine micromodel systems (COBM) at different wettability conditions through adjustment of brine composition. No COBM system has yet been identified that is so strongly water-wet that a crude oil is trapped in the traditional form of disconnected blobs commonly encountered in laboratory studies of trapping and mobilization of refined oil. Wettability conditions induced by crude oil tend to inhibit the snap-off mechanism by which oil becomes trapped as blobs at very strongly water-wet conditions. In laboratory studies of displacement of oil from single model pores, inhibition of snap-off has been shown to occur even when contact angles are comparatively low $\left(60^{\circ}\right)$ (Yu and Wardlaw, 1986).

Zhou et al (2000) investigated interrelationship of wettability, initial water saturation, aging time, and oil recovery by spontaneous imbibition and waterflooding, on numerous complex interactions. The wettability of COBR systems prepared using Prudhoe Bay crude oil, a synthetic formation brine, and Berea sandstone was varied by systematic change in initial water saturation and length of aging time at the reservoir temperature $\left(88^{\circ} \mathrm{C}\right)$. All displacement tests were done at ambient temperature. Various degrees of water wetness were achieved and quantified by a modified Amott wettability index $\left(\mathrm{I}_{\mathrm{w}}{ }^{\prime}\right)$ to water. Pairs of spontaneous imbibition (oil recovery by spontaneous imbibition of water) and waterflood (oil recovery vs. pore volumes of water injected) curves were measured for each of the induced wetting states. Fig. 8 shows the relationship between oil recovery by imbibition $\mathrm{R}_{\mathrm{im}}$ and $\mathrm{I}_{\mathrm{w}}{ }^{\prime}$, as well as the correlation between oil recovery by waterflood $\mathrm{R}_{\mathrm{wf}}$ and $\mathrm{I}_{\mathrm{w}}{ }^{\prime}$, the results demonstrate the highly significant effect of wettability on the waterflood and imbibition recoveries.

Graue et al (1999) established a wide range of reproducible wettability conditions for outcrop chalk cores by different procedures. Best reproducibility was obtained 


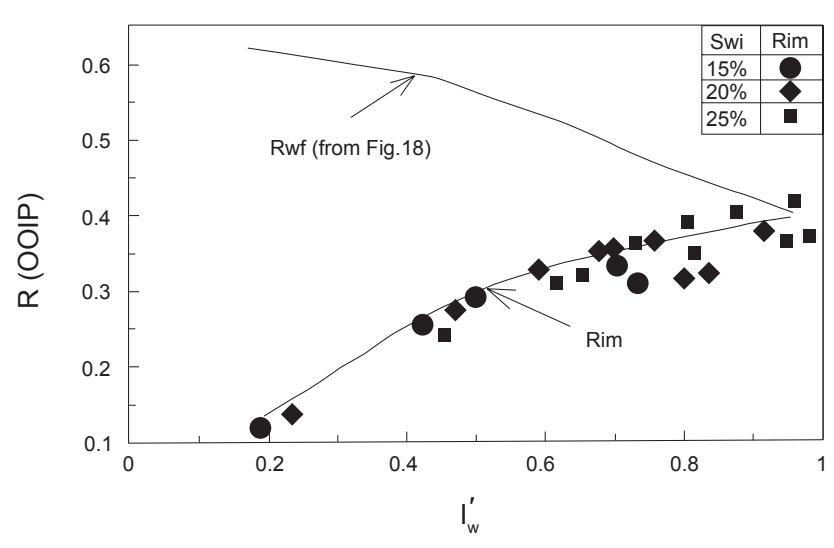

Fig. 8 Oil recovery by imbibition $R_{i m}$ and by waterflood $R_{w f} v s$. Amott wettability index to water (after Zhou et al, 2000)

when crude oil used for aging was replaced with decane after aging but before spontaneous imbibition started. A consistent change in wettability towards a less water-wet state with increased aging time was observed (see Fig. 9).

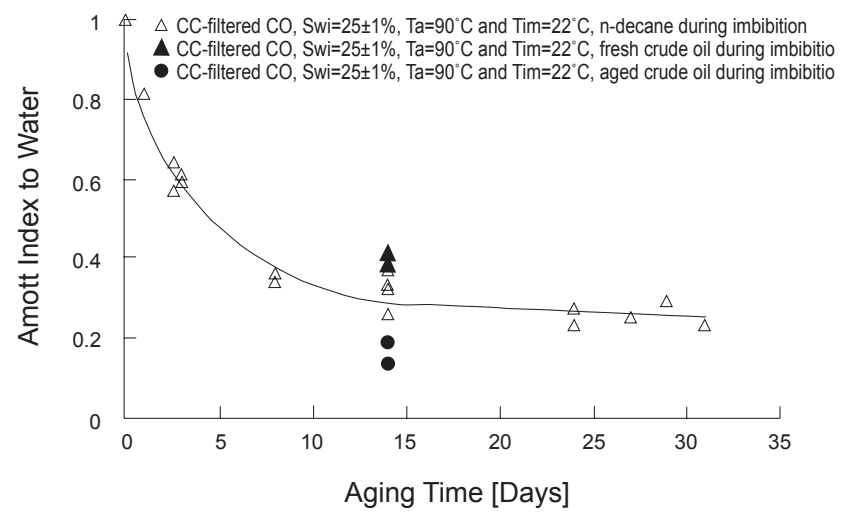

Fig. 9 Amott wettability index for water vs. aging time for the different procedures (after Graue et al, 1999)

The total oil recoveries, after spontaneous imbibition followed by a high rate water flood conducted in these carefully prepared chalk cores, were shown in Fig. 10. The results indicated the highest oil recovery for weakly waterwet cores (close to neutral wettability, $\mathrm{I}_{\mathrm{w}} \approx 0.3$ ). This is in agreement with work on sandstone. The difference in total oil recovery for weakly water-wet and strongly water-wet cores is about $10 \%$ of original oil in place (OOIP). This result indicates that wettability has a dominant effect on total water flooding oil recovery for chalk.

Rao et al (1992) summarized their laboratory results and field recovery trends of three Alberta reservoirs in both waterflood and miscible flood and found that they correlated well each other, showing that the intermediately-wet Gilwood system yielded the highest waterflood oil recoveries, the water-wet Beaverhill Lake system was next and the oilwet Crossfield Cardium system was the least effective. The response to miscible flood was quite different in that the oilwet Crossfield Cardium system yielded the highest recovery followed by the intermediately-wet Gilwood system and then by the water-wet Beaverhill Lake system. The effect of wettability on miscible flood recoveries could be attributed to the extent of water-shielding. The mixed-wet system of the Berea core with Gilwood fluids showed excellent recoveries in both waterflood and miscible flood. The mixed-wet system possesses the best of both worlds in that it has the benefit of continuous oil-wet paths in the larger pores through which oil can drain during waterflood, and yet it does not have the limitations of water-shielding during continuous slug miscible flooding. This demonstrated the need for including reservoir wettability in formulating production strategies.

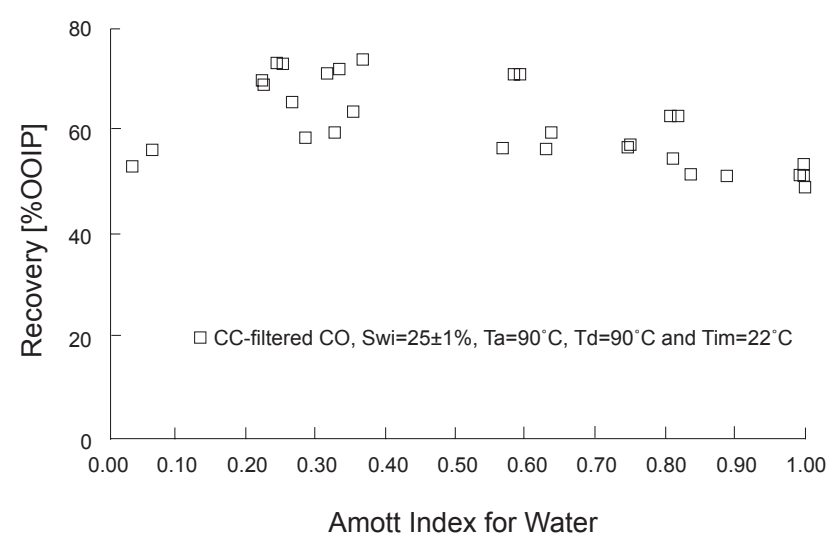

Fig. 10 Oil recovery after waterflooding vs. Amott wettablity index for water (after Graue et al, 1999)

Recently, Johannesen and Graue (2007) carried out a series of displacements of oil by water injection at constant pressure to determine the relation between oil recovery and applied capillary number in waterflood at different wettability conditions using outcrop chalk cores. The results showed that oil recovery had a maximum value when the wettability was about $I_{w}=0.3$. Optimum oil recovery shifted toward less water-wet conditions when the capillary number increased. Significant trapped oil after completed spontaneous water imbibition was mobilized at moderately water-wet to nearly neutral-wet conditions.

Recent studies by Song et al (2008) also proved that alteration of core wettability to an intermediate wetting state results in the highest oil recovery in core flooding tests by synthetic brine under various permeabilities.

It can be argued that the maximum in oil recovery at near-neutral wettability is obtained because capillary forces are minimized. However, it is the effect of wettability on fluid configurations and interface instabilities, rather than the absolute magnitude of capillary forces, that determines oil-displacement efficiency. Extensive investigation would be still needed before attempts can be made to explain the overall form of the relationship between oil recovery (and residual oil) and wettability.

\section{Recovery of oil by reservoir wettability alteration}

In the forgoing statements and discussion, reservoir wettability has significant effect on oil recovery, favorable alteration of reservoir wettability will help mobilize residual oil and get more oil from reservoirs. 


\subsection{Wettability alteration of carbonate reservoirs}

Due to original oil-wet or less water-wet status of carbonate reservoirs, injected water will not penetrate easily into less water-wetting porous matrices and so cannot displace that oil in place. The wettability alteration of carbonate reservoirs to preferentially more water-wet conditions will be beneficial to oil recovery, where spontaneous imbibition was discovered and has been recognized as a significant mechanism for improving oil recovery (Jadhunandan and Morrow, 1991; Zhou et al, 2000; Morrow and Mason, 2001).

More attention has been paid to chalk cases due to existing enhanced oil recovery (EOR) potential in fractured chalk reservoirs (Milter and Austad, 1996; Austad and Milter, 1997; Alveskog et al, 1998; Austad et al, 1998; Spinler et al, 2000; Standnes and Austad, 2000a; 2000b; Chen et al, 2001). Many research groups are currently active in various aspects of wetting and imbibition, topics range from molecular modeling of interface movement to studies of field scale reservoir performance. Recently, EOR methods based on chemically induced wettability alteration have gained a great deal of attention (Hirasaki and Zhang, 2004; Ayirala et al, 2006; Xu et al, 2006; Zhang et al, 2007; Wu et al, 2008). In these methods, chemicals such as surfactant solutions are injected into reservoirs and the matrix is flooded, altering its surface wettability from oil-wet to more water-wet, yielding higher ultimate recovery.

Vijapurapu and Rao (2004) studied the capability of certain ethoxy alcohol surfactants (nonionic surfactants) to alter wettability of the Yates reservoir rock (dolomite surface) (Fig. 11). Addition of this surfactant decreased the interfacial tension between Yates Crude oil and Yates brine from 29 to $0.19 \mathrm{dyne} / \mathrm{cm}$ at 3,500 $\mathrm{ppm}$ of surfactant concentration. This is accompanied by a decrease in water-advancing angle from 156 (strongly oil-wet) on smooth dolomite surface with no surfactant to 39 (water-wet) at a surfactant concentration of $3,500 \mathrm{ppm}$. This reduction in water-advancing contact angle signifies a change in wettability from a strongly oil-wet to a water-wet condition induced by surfactant. Such a large shift in wettability is beneficial in improving oil recovery due to imbibition from fractured oil-wet reservoirs.

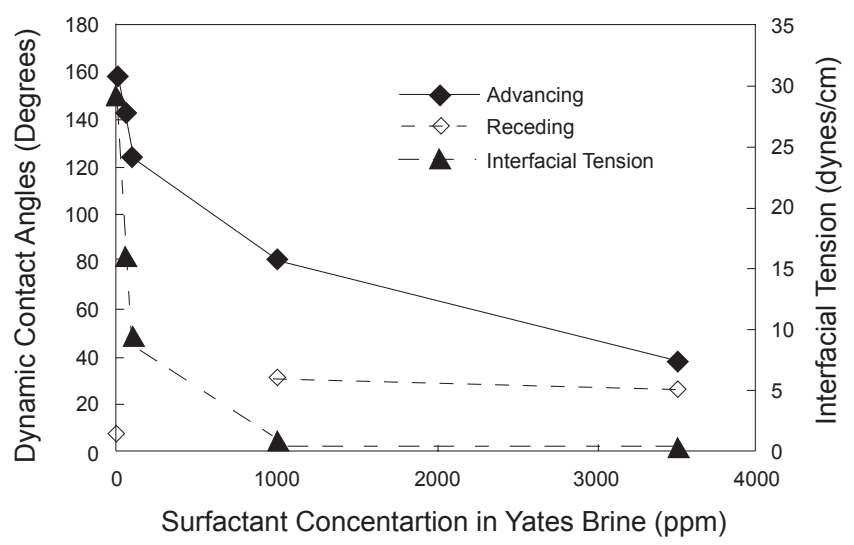

Fig. 11 Effect of ethoxy alcohol surfactant concentration on interfacial tension and dynamic contact angles using the DDDC technique for Yates crude oil-Yates brine-dolomite system (after Vijapurapu and Rao, 2004)
Several anionic surfactants (alkyl aryl ethoxylated sulfonate and propoxylated sulfates) in the presence of $\mathrm{Na}_{2} \mathrm{CO}_{3}$ could change a calcite surface wetted by a West Texas crude oil to intermediate/water-wet conditions as well as, or even better than, an efficient cationic surfactant (DTAB) (Seethepalli et al, 2004). The adsorption of the sulfonate surfactants can be suppressed significantly by the addition of $\mathrm{Na}_{2} \mathrm{CO}_{3}$. Greater than 50\% OOIP can be recovered from oilwet carbonate cores by spontaneous imbibition of $0.05 \mathrm{wt} \%$ anionic surfactant solutions on the laboratory-scale. Zhang et al (2006) also reported similar results.

Cationic surfactants of the type $\mathrm{C}_{n} \mathrm{TAB}$ (alkyl trimethyl ammonium bromide) were shown to promote spontaneous imbibition in carbonate porous medium (Standnes and Austad, 2000b; 2003a; 2003b). The mechanism for the wettability alteration was proposed to be desorption of strongly adsorbed organic carboxylates from the carbonate surface by the formation of ion-pairs with the surfactant monomer. These are then dissolved in the oil phase and micelles (see Fig. 12). While anionic surfactants are generally not able to desorb organic carboxylates adsorbed to the surface to change the wettability in an irreversible way, a possible interpretation is the formation of a surfactant double layer as shown schematically by Fig. 13. The EO (ethyoxyl)-surfactant is supposed to be adsorbed with the hydrophobic part onto the hydrophobic surface of the chalk. The hydrophilic head-group of the surfactant, the EO-groups and the anionic sulfonate group, may decrease the contact angle below $90^{\circ}$ by forming a small water zone between the organic coated surface and the oil. In this way, weak capillary forces are then created during the imbibition process. The fact that the imbibition of surfactant solution increases with increasing number of EOgroups supports such a mechanism. The formation of the surfactant double layer must not be regarded as a permanent wettability alteration of the chalk. In fact, it will probably be fully reversible due to the weak hydrophobic bonds between the surfactant and the hydrophobic surface. Thus, if the core is surrounded by oil, the pre-imbibed aqueous surfactant solution may be displaced by the oil again. It can be noticed that the ethoxylated carboxylate, $n-\mathrm{C}_{8}-(\mathrm{EO})_{8^{-}}$ $\mathrm{OCH}_{2} \mathrm{COONa}$, only displaced trace amounts of oil, probably due to the weak hydrophobic interaction between the $n-\mathrm{C}_{8}$ group and the hydrophobic surface and complex formation with $\mathrm{Ca}^{2+}$. The other anionic surfactants tested did not imbibe in any significant amounts of water into the oil-wet chalk, confirming that the EO-groups play a very important role concerning the imbibition mechanism.

Standnes et al (2002) investigated oil recoveries from oil wet reservoir cores and compared those using aqueous solutions of a nonionic surfactant (ethoxylated alcohol, EA) and a cationic surfactant $\left(\mathrm{C}_{12} \mathrm{TAB}\right)$. The experiments were conducted at room temperature using short (approximately $5 \mathrm{~cm}$ ) and long (approximately $30 \mathrm{~cm}$ ) cores with initial water saturation in the range of $17 \%-33 \%$. In general, the efficiency of $\mathrm{C}_{12} \mathrm{TAB}$ was superior to EA regarding spontaneous oil expulsion from the cores. For the short core experiments, about $40 \%-45 \%$ of OOIP was recovered using $\mathrm{C}_{12} \mathrm{TAB}$, while $10 \%$ was the average recovery using EA. 

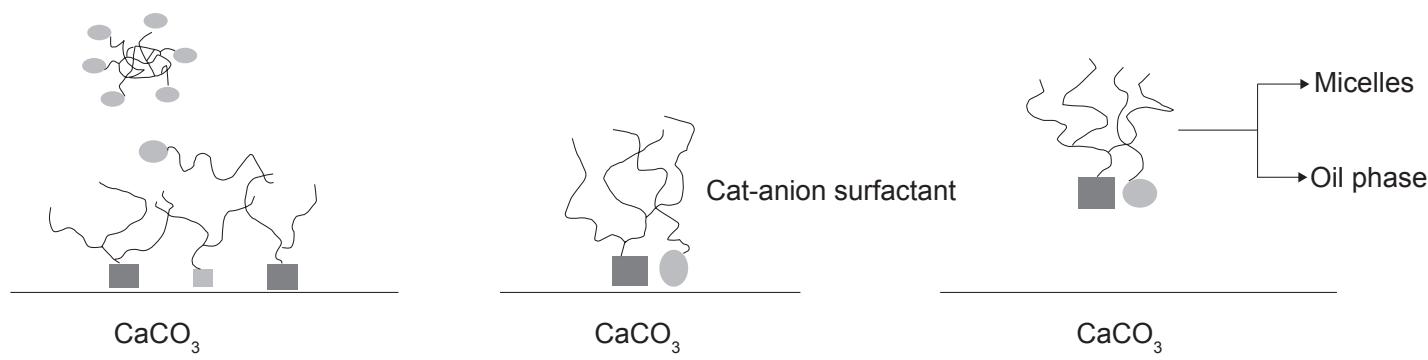

Fig. 12 Wettability alteration mechanism of carbonate by cationic surfactants. Large squares: anionic carboxylate groups; $-\mathrm{COO}^{-}$small squares: other polar components; circles: cationic ammonium group; $-\mathrm{N}^{+}\left(\mathrm{CH}_{3}\right)_{3}($ after $\mathrm{Zhang}$ et al, 2006)

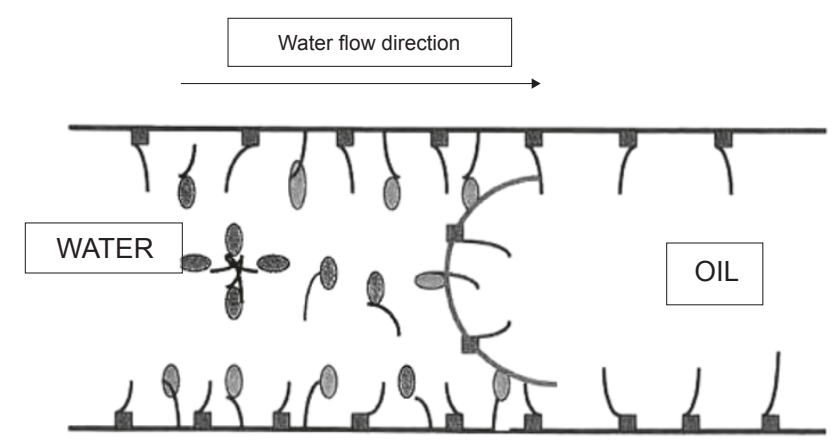

Fig. 13 Schematic illustration of the mechanism for bi-layer formation in a pore using EO-sulfonates. Ellipses symbolize EO-sulfonates, and squares symbolize organic carboxylates from the oil (after Standnes and Austad, 2003)

The imbibition rate of EA solution into the long core with a permeability of $45 \mathrm{mD}$ was as small as $5 \%$, while large improvements were achieved when changing to $\mathrm{C}_{12} \mathrm{TAB}$ solution. Contact angle measurements on oil-wet calcite crystals confirmed that $\mathrm{C}_{12} \mathrm{TAB}$ was much more effective than EA in altering wettability toward more water-wet conditions. The mechanism of ion pair formation by $\mathrm{C}_{n} \mathrm{TAB}$ with acidic components in crude oil was verified experimentally to be dominant in wettability alteration of carbonates (Yao and $\mathrm{Li}$, 2009).

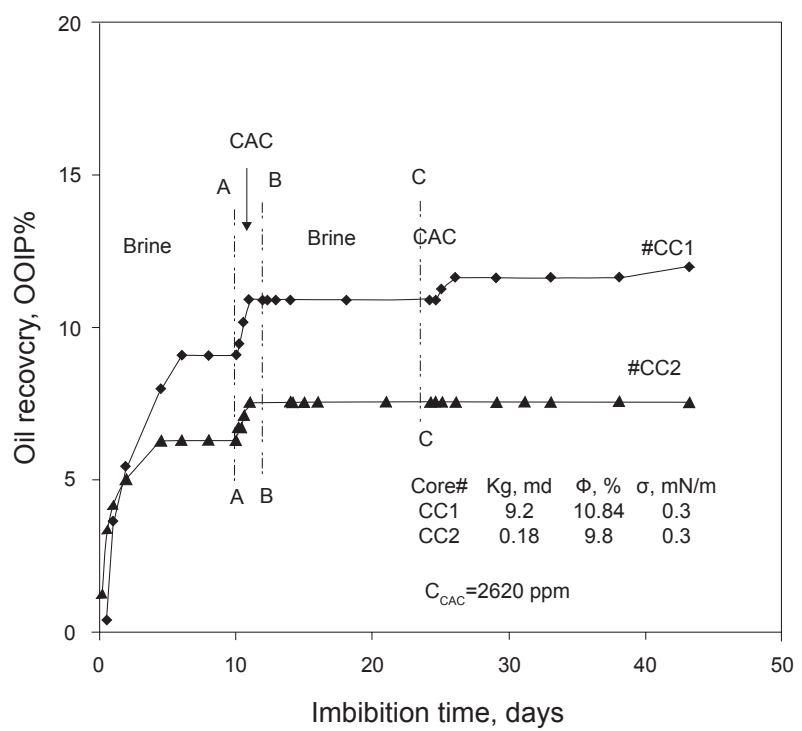

(a)
$\mathrm{Wu}$ et al (2008) reported similar results that cationic surfactants were generally more efficient in recovering model oil from limestone, which was also consistent with the evaluation results of wettability alteration which was evaluated by flotation tests. But Xie et al (2005) and Weiss and Xie (2007) reported different results that some surfactants had good performances on some cores, while other surfactants had no positive effects on certain cores. In their work, promotion of imbibition was determined for a cationic surfactant, cocoalkyltrimethyl ammonium chloride (CAC), and a nonionic surfactant, an ethoxylated alcohol (POA). Tested cores from three dolomitic Class II reservoirs showed very weak waterwetness. When reservoir brine was used as the imbibition fluid, oil recovery was in the range of 0 to $35 \%$ of OOIP. In subsequent imbibition of surfactant solutions at or somewhat above the critical micelle concentration (CMC), nearly all cores can further imbibe surfactant solutions, to recover $5 \%$ to $15 \%$ of OOIP. Comparison of scaled results for imbibition of brine vs. surfactant indicated that a shift in wettability toward increased water-wetness was approximately the same for both cationic and nonionic surfactants. Generally, the rate of oil recovery by spontaneous imbibition from dolomite cores treated with nonionic surfactants tended to be faster than that with cationic surfactants, probably due to the higher IFT of the former with the crude oil (see Fig. 14).

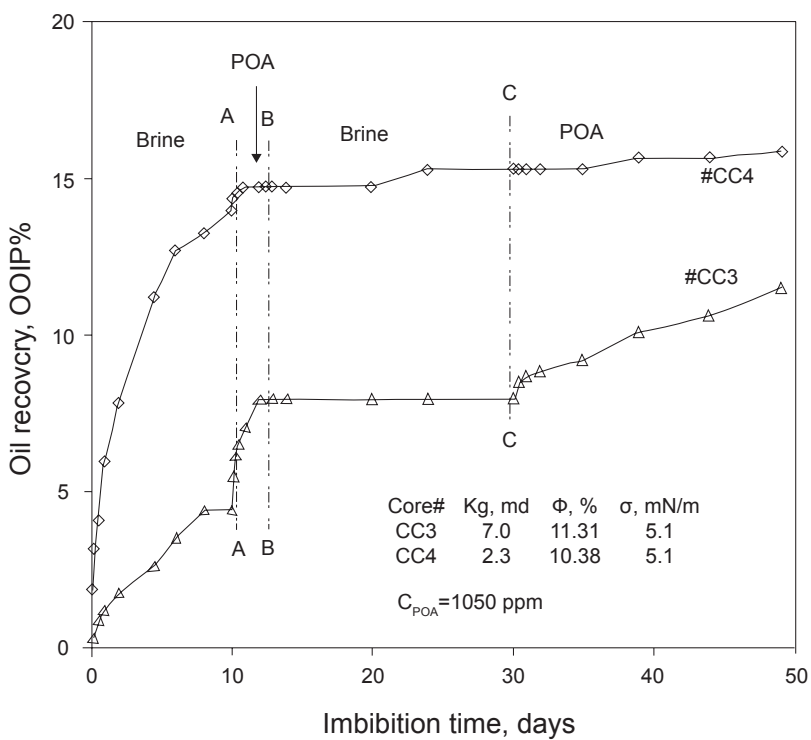

(b)

Fig. 14 Oil recovery by imbibition for sequential soaking in brine and surfactant (a) Brine/cationic surfactant; (b) brine/nonionic surfactant (after Xie et al, 2005) 
More recently, Tabary et al (2009) carried out experiments to improve oil recovery in carbonate formations with chemicals including $\mathrm{Na}_{2} \mathrm{CO}_{3}$ and surfactant of sulfated propoxylated alcohols. The experimental results showed that the alkali exhibited a striking imbibition enhancement for outcrop carbonate cores with a reactive crude oil, while imbibition was moderate for non-reactive mineral oil in the presence of alkali without surfactants. The formulations containing surfactants and alkalis were evaluated for imbibition performance in correlation with interfacial tension, which proved the influence of surfactants on interfacial tension to be the primary factor for oil recovery. The surfactants generated in-situ from reactive oil by alkali are responsible for the wettability alteration.

Basically, due to the chemical consistency of carbonate reservoirs, the reference system for wettability alteration investigation for this type of reservoirs is relatively determined, and the emphasis should be focused on innovative control of the imbibition capability of formations by appropriate chemical systems to accomplish faster and higher level imbibition, which is crucial in oil recovery.

\subsection{Wettability alteration of sandstone reservoirs}

The situations seem far different and more complex in the case of sandstone reservoirs, whose wettability may vary widely from strongly water-wet to strongly oil-wet states, with many falling in the mid-band of neutral or intermediate wettability where the rock shows equal preference to both oil and water. And spontaneous imbibition can not be the uppermost EOR mechanism in sandstone reservoirs.

Another factor we have to take into account is that sandstone reservoirs generally undergo waterflood, on which the wettability has significant influence. The process has been studied for several decades and the published literature is supporting the concept that there is a maximal waterflood recovery near neutral wettability (Morrow et al, 1984; Morrow, 1990; Jadhunandan and Morrow, 1995; Zhou et al, 2000; Johannesen and Graue, 2007). There are also several reports in the literature, which indicate that the waterflood recovery is better in water-wet cores than in oil-wet ones (Anderson, 1987). However, Rathmell et al (1973) found in their waterflood experiments in 7 to $9 \mathrm{ft}$ long Berea cores that as the core became less water-wet (or shifted toward intermediate wettability), both the breakthrough and ultimate oil recoveries was promoted. These results can be explained on the basis of weak capillary forces in weakly water-wet or intermediately-wet cores, where oil is trapped in strongly water-wet cores with imbibition of water into the smaller pore spaces and by-passing oil in large pores. The zone of two-phase flow under these conditions is short. The oil bypassed in large pores is surrounded by water and is immobile except at higher pressure gradients. With the capillary forces weakened (that is, as the system becomes weakly water-wet or intermediately-wet), the tendency toward rapid imbibition and trapping of oil in large pores by movement of water through small pores should be diminished. The zone of twophase flow should become longer and displacement of oil to lower saturations should be possible.
Some studies conducted by Rao et al (2006) indicated that the surfactant-induced wettability alteration process appeared to be beneficial for field implementation in oilwet reservoirs. In oil-wet reservoirs, surfactants can induce wettability alterations to either less oil-wet or water-wet state, resulting in improved oil recovery. In initially waterwet reservoirs, the surfactant-induced wettability alteration process is beneficial only if the surfactant induces either mixed wettability or intermediate wettability. This process is detrimental for improved oil recovery if the surfactant induces oil-wet behavior. Thus, the surfactant type (ability to result in favorable wettability alteration), rock mineralogy and the surfactant concentration are critical in determining the economic success for this process in the field. Improper determination of original reservoir wettability can lead to poor decisions for improved oil recovery field applications using surfactants. Hence, the surfactant must be carefully chosen depending on initial reservoir wettability to maximize the benefit. Therefore, laboratory studies involving accurate reservoir wettability characterization and its alteration under reservoir conditions are essential for the success of any improved oil recovery process using surfactants in the field.

Recently, Ayirala and Rao (2006) performed waterflood using two different sandstone-fluids systems to explore the relative contributions from IFT reduction and wettability alteration mechanisms due to surfactants on enhanced oil recovery. The experiments clearly demonstrated that the wettability-altering capability of surfactants was the principal mechanism for enhancing oil recovery. This study provided evidence that the surfactant was able to render a special kind of heterogeneous wettability, known as mixed wettability, which enables preferential draining of the oil phase through the formation of continuous wetting films of oil on the rock surface.

The wettability alteration performance of surfactants significantly relies on their type and structure, and the mechanism for various surfactants is certainly different. The adsorption of surfactants can be investigated by various techniques such as atomic force microscopy (Seiedi et al, 2011), ATR-FTIR (Tabor et al, 2009a; 2009b), quartz crystal microbalance (Hodges et al, 2009) and molecular simulation (Li et al, 2009; Lu et al, 2009; Song et al, 2009a; Wang et al, $2009 \mathrm{~b}$ ), and the wettability alteration process can be explored by correlation of contact angle, adhesional tension, and surface free energy, etc. with surfactant molecular structure and concentration.

Due to the chemical complexity of sandstones, which contain quartz and clay cements, the wettability alteration mechanism in sandstones should include the process on both components, and investigate the wettability alteration on the surface of the two different components respectively. Much work has been accomplished on the adsorption of various types of surfactants on quartz. Due to the electronegativity of the quartz surface, cationic surfactants show more efficiency than other types of surfactants, and the correlation between contact angle and adsorption isotherm has also confirmed the trend (Zhang et al, 2010). Besides adsorption of surfactants on quartz, concerning the chemical similarity of mica with clay, some research on surfactant adsorption on mica 
was carried out. Recently, the investigation of wettability alteration by Triton X-100 and $\mathrm{C}_{16}$ TAB on mica by atomic force microscopy combined with contact angle measurement by Seiedi et al (2011) indicated that the former can change crude oil aged mica surface to water-wet, while the latter altered the aged mica surface to more oil-wet. Two different mechanisms of surface cleaning and surfactant adsorption for Triton X-100 and $\mathrm{C}_{16} \mathrm{TAB}$, respectively, were proposed.

Although the adsorption mechanism of various surfactants on quartz and mica has produced many useful results, the effect of surfactants on wettability of sandstones still needs more effort to clarify its influence on the heterogeneous wettability, fluid flow in characteristic intergranular pores in sandstones, and therefore the distribution of water and oil before and after wettability alteration, which is crucial for the design and implementation of EOR techniques for sandstone reservoirs by surfactant wettability alteration.

\section{Other concerning aspects on EOR by wettability alteration}

Based on current knowledge of wettability alteration induced by different chemicals, surfactant looks the most efficient. But EOR by wettability alteration using surfactant solution would become complicated because of another performance of surfactant - reduction of IFT, which can also influence capillary pressure.

Different aspects of capillary imbibition of a low IFT aqueous phase were studied in the past (Schechter et al, 1994; Al-Lawati and Saleh, 1996). More research is needed to clarify the effects of surfactant addition in aqueous phase on the capillary imbibition recovery rate and ultimate recovery and to understand the mechanism of the low IFT imbibition. The changes on rock-fluid and fluid-fluid interactions due to surfactant addition could act in different ways in oil recovery by capillary imbibition. It has been observed that the reduction in IFT yields higher ultimate recovery but slower imbibition rate for water wet sandstone samples (Cuiec et al, 1994; Babadagli et al, 1999). Schechter et al (1994) observed the same effect for iso-octane recovery from limestone whereas Babadagli (2003a; 2003b) reported that the capillary imbibition of low IFT solution (with a nonionic surfactant) was faster than the high IFT case when a light crude oil is used with a limestone sample. Austad et al (1998) observed the same effect for chalks with a cationic surfactant. Keijzer and Vries (1993) showed that the surfactant imbibition did not yield any incremental recovery for water-wet sandstone but some effects were observed on the recovery rate. Sheng et al (2010) demonstrated by analytical model and numerical simulation that in carbonate reservoirs, wettability alteration only plays important roles when the IFT is high, and it is effective in the early stages. IFT plays very important roles with or without wettability alteration and is effective during the entire process.

In case of unfavorable matrix boundary conditions, that do not allow interaction from all sides of the matrix, surfactant solution may yield lower ultimate recovery and lower recovery rate than those of brine (Babadagli et al, 1999; Babadagli, 2000). In addition to the physical boundary condition, the interaction could be controlled by the strength of the capillary forces that eventually yields co- or countercurrent (or both) interaction. This might eventually affect the ultimate recovery and recovery rate (Schechter et al, 1994; Austad and Milter, 1997). As the capillary forces become stronger, i.e., strongly water wet rocks or higher IFT, the capillary imbibition dominates the recovery. So we can expect fully counter-current type interaction for this case. As the capillary forces weaken, i.e., larger matrix block sizes or less water wet rock or lowered IFT, the effect of gravity on interactions between matrix and fractures could be expected, which might cause a fully co-current matrix-fracture transfer.

Wettability alteration by surfactant addition into brine can be expected depending on the rock and surfactant type. Incompatibility of the rock with surfactant type might give rise to adsorption, which both play a role on the recovery rate and ultimate recovery. Surfactant degradation due to factors other than temperature is another possibility as well. Thus, the performance of the surfactant solution as an imbibition fluid could be controlled by the rock properties (wettability, lithology, matrix boundary condition and adsorption) and the characteristics of surfactant. Therefore, the selection of proper surfactant type and amount for different rock and oil types is the key factor. Due to complexities caused by so many parameters involved in the process, no procedure has so far been suggested in terms of the selection of the surfactant type and the application of the technique for effective capillary imbibition recovery in naturally fractured reservoirs.

Babadagli (2005) systematically analyzed oil recovery by spontaneous imbibition of surfactant solution in three different types of reservoirs. Different recovery rates and ultimate recoveries were obtained for different surfactant types in different reservoir samples, and two different behavior patterns were observed. Nonionic surfactant solution increased the recovery rate and ultimate recovery of heavy-oil in water-wet sandstones compared to brine imbibition (high IFT), while no such effect was observed for the recovery rate of the counter-current imbibition (imbibition taking place only from one side of the core) for lighter crude oil even though a slight increase in the ultimate recovery was obtained by the addition of surfactant, except light oil cases such as kerosene and light crude oil in sandstones. In all cases (limestones, sandstones with heavy-crude, and chalk samples) the same surfactant solution (a nonionic surfactant) yielded a higher ultimate recovery and faster recovery rate, while low IFT (higher anionic surfactant concentration) yielded higher recovery than the brine case in chalks. Lower surfactant concentration, however, resulted in even lower recovery than the brine case. A nonionic surfactant, on the other hand, showed very effective recovery regardless of the concentration of surfactant.

$\mathrm{Xu}$ et al (2008) investigated surfactant induced interfacial interactions at reservoir conditions and reported that all concentrations of anionic surfactant (ethoxy sulfate) were effective in altering the wettability of a strongly oil-wet stocktank-oil/brine/dolomite system to a less oil-wet state. An anionic surfactant is also effective in altering the wettability of initially weakly water-wet live-oil/brine/dolomite system to a strongly oil-wet state. The injection of a nonionic 
surfactant (ethoxy alcohol) at different concentrations showed no significant influence on the strongly oil-wet stock-tankoil/brine/dolomite system, but it increased the contact angles of the live-oil/brine/dolomite system from $55^{\circ}$ to $85^{\circ}$ (from water-wet to intermediate-wet). The wettability alterations to a strongly oil-wet state observed with anionic surfactant in a live-oil system indicate the possibility to develop mixedwettability (formation of continuous oil-wet films on the rock surface) using this surfactant for potential oil-recovery improvements.

Furthermore, enhanced oil recovery by spontaneous imbibition has generally an apparent disadvantage, i.e. a very slow imbibition rate, which depends on capillary forces, gravitational forces (or buoyancy forces), matrix boundary conditions, and their interactions (Stoll et al, 2008). The behavior of fluids in micropores controlled by wettability can be analyzed with fluid dynamics theory to encompass all these parameters into an integrated micromodel (Wang et al, 2009), which is promising in prediction of oil recovery with models established according to specific reservoir conditions.

\section{Concluding remarks}

Research on wettability and its effects on oil recovery spans half a century and efforts to enhance recovery of oil by reservoir wettability alteration are still continuing. However, many questions of fundamental and practical importance have, as yet, far from complete answers. Surfactant induced wettability processes appear to be beneficial for field implementation in oil-wet reservoirs, but studies indicate that the enhanced recovery of oil by surfactant treatment depends on wetting characteristic, rock mineralogy, porosity, permeability, pore heterogeneity, matrix boundary conditions, saturation, oil/water IFT, gravity (or buoyancy force), capillary number, surfactant type, surfactant adsorption property, surfactant molecular diffusion coefficient, etc., which must be evaluated individually. Based on above mentioned knowledge, technical interest is likely to continue for the coming years with emphasis on low permeability fractured reservoirs.

Another technical interest would be development of forced imbibition, which combines the merits of oil recovery of waterflood and imbibition. Waterflood pressure gradient will manifestly accelerate sequential diffusion-imbibition processes, resulting in high ultimate recovery rate and fast recovery rate. On the other hand, by using surfactant, the capillary number can be increased by the coupling of IFT reduction and wettability alteration, resulting in higher oil recovery.

\section{References}

Al-Lawati S and Saleh S. Oil recovery in fractured oil reservoirs by low IFT imbibition process. SPE Annual Technical Conference and Exhibition, 1996, Denver, Colorado (paper SPE 36688)

Alveskog P L, Holt T and Torsaeter O. The effect of surfactant concentration on the Amott wettability index and residual oil saturation. Journal of Petroleum Science and Engineering. 1998. 20(3-4): 247-252

Amott E. Observations relating to the wettability of porous rock.
Petroleum Transactions. 1959. 216: 156-162

Anderson W G. Wettability literature survey-Part 1: Rock/oil/brine interactions and the effects of core handling on wettability. Journal of Petroleum Technology. 1986a. 38(10): 1125-1144 (paper SPE 13932)

Anderson W. Wettability literature survey-Part 2: Wettability measurement. Journal of Petroleum Technology. 1986b. 38(11): 1246-1262 (paper SPE 13933)

Anderson W G. Wettability literature survey-Part 6: The effects of wettability on waterflooding. Journal of Petroleum Technology. 1987. 39(12): 1605-1622 (paper SPE 16471)

Austad T, Matre B, Milter J, et al. Chemical flooding of oil reservoirs 8 . Spontaneous oil expulsion from oil- and water-wet low permeable chalk material by imbibition of aqueous surfactant solutions. Colloids and Surfaces A: Physicochemical and Engineering Aspects. 1998. 137(1-3): 117-129

Austad T and Milter J. Spontaneous imbibition of water into low permeable chalk at different wettabilities using surfactants. International Symposium on Oilfield Chemistry, 1997, Houston, Texas (paper SPE 37236)

Ayirala S C and Rao D N. Contact Angle, Wettability and Adhesion, Vol 4. Leiden: VSP. 2006. 369-384

Ayirala S C, Vijapurapu C S and Rao D N. Beneficial effects of wettability altering surfactants in oil-wet fractured reservoirs. Journal of Petroleum Science and Engineering. 2006. 52(1-4): 261-274

Babadagli T. Scaling of co-current and counter-current capillary imbibition for surfactant and polymer injection in naturally fractured reservoirs. SPE/AAPG Western Regional Meeting, 2000, Long Beach, California (paper SPE 62848)

Babadagli T. Evaluation of EOR methods for heavy-oil recovery in naturally fractured reservoirs. Journal of Petroleum Science and Engineering. 2003a. 37(1-2): 25-37

Babadagli T. Selection of proper enhanced oil recovery fluid for efficient matrix recovery in fractured oil reservoirs. Colloids and Surfaces A: Physicochemical and Engineering Aspects. 2003b. 223(1-3): 157175

Babadagli T. Analysis of oil recovery by spontaneous imbibition of surfactant solution. Oil \& Gas Science and Technology. 2005. 60(4): 697-710

Babadagli T, Al-Bemani A and Boukadi F. Analysis of capillary imbibition recovery considering the simultaneous effects of gravity, low IFT, and boundary conditions. SPE Asia Pacific Improved Oil Recovery Conference, 1999, Kuala Lumpur, Malaysia (paper SPE 57321)

Brown R and Fatt I. Measurements of fractional wettability of oil fields' rocks by the nuclear magnetic relaxation method. 31st Annual Fall Meeting of the Petroleum Branch of AIME, 1956, Los Angeles (paper SPE 743)

Buckley J S, Liu Y and Monsterleet S. Mechanisms of wetting alteration by crude oils. SPE Journal. 1998. 3(1): 54-61 (paper SPE 37230)

Chatzis I, Morrow N R and Lim H T. Magnitude and detailed structure of residual oil saturation. SPE Journal. 1983. 23(2): 311-326 (paper SPE 10681)

Chen H, Lucas L, Nogaret L, et al. Laboratory monitoring of surfactant imbibition with computerized tomography. SPE Reservoir Evaluation \& Engineering. 2001. 4(1): 16-25 (paper SPE 69197)

Chen T P, Cui Z S and Zhang X J. Experimental study of the effect of reservoir rock wettability on oil recovery factor of low permeability oil reservoir. Journal of Xi' an Shiyou University (Natural Science Edition). 2009. 24(6): $42-45$ (in Chinese)

Chilingar G V and Yen T. Some notes on wettability and relative permeabilities of carbonate reservoir rocks, II. Energy Sources, Part A: Recovery, Utilization, and Environmental Effects. 1993. 7(1): 6775 
Craig F F. The Reservoir Engineering Aspects of Waterflooding. Richardson, TX, SPE. 1971

Cuiec L, Bourbiaux B and Kalaydjian F. Oil recovery by imbibition in low-permeability chalk. SPE Formation Evaluation. 1994. 9(3): 200208 (paper SPE 20259)

Dwarakanath V, Jackson R E and Pope G A. Influence of wettability on the recovery of NAPLs from alluvium. Environmental Science and Technology. 2002. 36(2): 227-231

Graue A, Viksund B G and Baldwin B A. Reproducible wettability alteration of low-permeable outcrop chalk. SPE Reservoir Evaluation and Engineering. 1999. 2: 134-140 (paper SPE 55904)

Hall A, Collins S and Melrose J. Stability of aqueous wetting films in Athabasca tar sands. SPE Journal. 1983. 23(2): 249-258 (paper SPE 10626)

Hatiboglu C and Babadagli T. Primary and secondary oil recovery from different-wettability rocks by countercurrent diffusion and spontaneous imbibition. 2006 SPE/DOE Symposium on Improved Oil Recovery, 2006, Tulsa, Oklahoma (paper SPE 94120)

Hirasaki G and Zhang D L. Surface chemistry of oil recovery from fractured, oil-wet, carbonate formations. SPE Journal. 2004. 9(2): 151-162

Hodges C, Biggs S and Walker L. Adsorption studies of a polymerizable surfactant by optical reflectivity and quartz crystal microbalance. Langmuir. 2009. 25(19): 11503-11508 (paper SPE 88365)

Jadhunandan P P and Morrow N R. Spontaneous imbibition of water by crude oil/brine/rock systems. In Situ. 1991. 15(4): 319-346

Jadhunandan P P and Morrow N R. Effect of wettability on waterflood recovery for crude-oil/brine/rock systems. SPE Reservoir Engineering. 1995. 10(1): 40-46 (paper SPE 22597)

Johannesen E and Graue A. Systematic investigation of waterflood reducing residual oil saturations by increasing differential pressures at various wettabilities. Offshore Europe, 2007, Aberdeen, Scotland, UK (paper SPE 108593)

Johannesen E B and Graue A. Mobilization of remaining oil—Emphasis on capillary number and wettability. International Oil Conference and Exhibition in Mexico, 2007, Veracruz, Mexico (paper SPE 108724)

Keijzer P P M and de Vries A S. Imbibition of surfactant solutions. SPE Advanced Technology Series. 1993. 1(2): 110-113 (paper SPE 20222)

Kennedy H T, Burja E O and Boykin R S. An investigation of the effects of wettability on oil recovery by water flooding. Journal of Physical Chemistry. 1955. 59(9): 867-869

Kovscek A, Wong H and Radke C. A pore-level scenario for the development of mixed wettability in oil reservoirs. AIChE Journal. 1993. 39(6): 1072-1085

Li X, Liu Y, Tang J, et al. Dissipative particle dynamics simulation of wettability alternation phenomena in the chemical flooding process. Acta Mechanica Sinica. 2009. 25(5): 583-587

Liu H Z, Li L C, Sun G L, et al. Influence of reservoir wettability on enhanced oil recovery. Chemical Engineering and Equipment. 2009. (10): 74-76 (in Chinese)

Lowe A, Phillips M and Riddiford A. On the wetting of carbonate surfaces by oil and water. Journal of Canadian Petroleum Technology. 1973. 12(2): 33-40 (paper SPE 73-02-04)

Lu G, Zhang X, Shao C, et al. Molecular dynamics simulation of adsorption of an oil-water-surfactant mixture on calcite surface. Petroleum Science. 2009. 6(1): 76-81

Melrose J. Interpretation of mixed wettability states in reservoir rocks. SPE Annual Technical Conference and Exhibition, 1982, New Orleans, Louisiana (paper SPE 10971)

Milter J and Austad T. Chemical flooding of oil reservoirs 6. Evaluation of the mechanism for oil expulsion by spontaneous imbibition of brine with and without surfactant in water-wet, low-permeable, chalk material. Colloids and Surfaces A: Physicochemical and Engineering
Aspects. 1996. 113(3): 269-278

Morrow N, Cram P and McCaffery F. Displacement studies in dolomite with wettability control by octanoic acid. Old SPE Journal. 1973. 13(4): 221-232 (paper SPE 3993)

Morrow N R, Lim H T and Ward J S. Effect of crude-oil-induced wettability changes on oil recovery. 59th Annual Society of Petroleum Engineers of AIME Technical Conference, 1984, Houston, Texas (paper SPE 13215)

Morrow N R. Wettability and its effect on oil recovery. Journal of Petroleum Technology. 1990. 24(12): 1476-1485 (paper SPE 21621)

Morrow N R. Interfacial Phenomena in Petroleum Recovery. New York: Marcel Dekker. 1991. 1-22, 319-376

Morrow N R and Mason G. Recovery of oil by spontaneous imbibition. Current Opinion in Colloid \& Interface Science. 2001. 6(4): 321337

Rao D, Girard M and Sayegh S. The influence of reservoir wettability on waterflood and miscible flood performance. Journal of Canadian Petroleum Technology. 1992. 31(6): 47-55 (paper SPE 92-06-05)

Rao D N, Ayirala S C, Abe A A, et al. Impact of low-cost dilute surfactants on wettability and relative permeability. SPE/DOE Symposium on Improved Oil Recovery, 2006, Tulsa, Oklahoma (paper SPE 99609)

Rathmell J, Braun P and Perkins T. Reservoir waterflood residual oil saturation from laboratory tests. Journal of Petroleum Technology. 1973. 25(2): 175-185 (paper SPE 3785)

Robin M, Rosenberg E and Fassi-Fihri O. Wettability studies at the pore level: A new approach by the use of cryo-scanning electron microscopy. SPE Formation Evaluation. 1995. 10(1): 11-19 (paper SPE 22596)

Salathiel R. Oil recovery by surface film drainage in mixed-wettability rocks. Journal of Petroleum Technology. 1973. 25(10): 1216-1224 (paper SPE 4104)

Schechter D S, Zhou D and Orr F M. Low IFT drainage and imbibition. Journal of Petroleum Science and Engineering. 1994. 11(4): 283-300

Seethepalli A, Adibhatla B and Mohanty K K. Physicochemical interactions during surfactant flooding of fractured carbonate reservoirs. SPE Journal. 2004. 9(4): 411-418 (paper SPE 89423)

Seiedi O, Rahbar M, Nabipour M, et al. Atomic force microscopy (AFM) investigation on the surfactant wettability alteration mechanism of aged mica mineral surfaces. Energy \& Fuels. 2011. 25(1): 183-188

Sheng J, Morel D and Gauer P. Evaluation of the effect of wettability alteration on oil recovery in carbonate reservoirs. AAPG GEO 2010 Middle East Geoscience Conference \& Exhibition, 2010, Manama, Bahrain

Smith J P, Francisco M A and Houser P J. Chemical and wetting interactions between Berea sandstone and acidic, basic, and neutral crude oil components. Energy \& Fuels. 1989. 3(3): 299-303

Song Q S, Guo X L, Yuan S L, et al. Molecular dynamics simulation of sodium dodecyl benzene sulfonate aggregation on silica surface. Acta Physio-Chimica Sinica. 2009a. 25(6): 1053-1058 (in Chinese)

Song X W, Cheng H R, Cao X L, et al. The effects of wettability on oil recovery efficiency. Journal of Petroleum University. 2009b. 22(4): 49-52 (in Chinese)

Song X W, Zhang L J, Cao X L, et al. Effects of wettability on oil and water flow through porous media. Oilfield Chemistry. 2008. 25(4): 305-308 (in Chinese)

Spinler E A, Zornes D R, Tobola D P, et al. Enhancement of oil recovery using a low concentration of surfactant to improve spontaneous and forced imbibition in chalk. SPE/DOE Improved Oil Recovery Symposium, 2000, Tulsa, Oklahoma (paper SPE 59290)

Standnes D C and Austad T. Wettability alteration in chalk: 1. Preparation of core material and oil properties. Journal of Petroleum Science and Engineering. 2000a. 28(3): 111-121

Standnes D C and Austad T. Wettability alteration in chalk: 2. 
Mechanism for wettability alteration from oil-wet to water-wet using surfactants. Journal of Petroleum Science and Engineering. 2000b. 28(3): 123-143

Standnes D C and Austad T. Wettability alteration in carbonates: Interaction between cationic surfactant and carboxylates as a key factor in wettability alteration from oil-wet to water-wet conditions. Colloids and Surfaces A: Physicochemical and Engineering Aspects. 2003a. 216(1-3): 243-259

Standnes D C and Austad T. Wettability alteration in carbonates: Lowcost ammonium surfactants based on bio-derivatives from the coconut palm as active chemicals to change the wettability form oil-wet to water-wet conditions. Colloids and Surfaces A: Physicochemical and Engineering Aspects. 2003b. 218(1-3): 161-173

Standnes D C, Nogaret L A D, Chen H-L, et al. An evaluation of spontaneous imbibition of water into oil-wet carbonate reservoir cores using a nonionic and a cationic surfactant. Energy \& Fuels. 2002. 16(6): 1557

Stoll W M, Hofman J P, Ligthelm D J, et al. Toward field-scale wettability modification-The limitations of diffusive transport. SPE Reservoir Evaluation \& Engineering. 2008. 11(3): 633-640 (paper SPE 107095)

Tabary R, Fornari A, Bazin B, et al. Improved oil recovery with chemicals in fractured carbonate formations. SPE International Symposium on Oilfield Chemistry, 2009, the Woodlands. Texas (paper SPE 121668)

Taber J. Research on enhanced oil recovery: Past, present, and future. Pure and Applied Chemistry. 1980. 52: 1323-1347

Tabor R F, Eastoe J and Dowding P. Adsorption and desorption of nonionic surfactants on silica from toluene studied by ATR-FTIR. Langmuir. 2009a. 25(17): 9785-9791

Tabor R F, Eastoe J and Dowding P. Adsorption and desorption of cationic surfactants onto silica from toluene studied by ATR-FTIR. Langmuir. 2009b. 26(2): 671-677

Treiber L and Owens W. A laboratory evaluation of the wettability of fifty oil-producing reservoirs. SPE Journal. 1972. 12(6): 531-540

Vijapurapu C S and Rao D N. Compositional effects of fluids on spreading, adhesion and wettability in porous media. Colloids and Surfaces A: Physicochemical and Engineering Aspects. 2004. 241(13): 335-342 (paper SPE 3526)

Wang F, Yue X A, Xu S L, et al. Influence of wettability on water flow in microtubes and cores. Chinese Science Bulletin. 2009a. 54(7): 972977 (in Chinese)

Wang P, Shi J B and Peng C J. Monte Carlo simulation on adsorption of nonionic gemini surfactant at solid-liquid interfaces. Journal of East China University of Science and Technology (Natural Science Edition). 2009b. 35(2): 245-249 (in Chinese)

Weiss W W and Xie X. Oilfield surfactants improve recovery by imbibition. International Symposium on Oilfield Chemistry, 2007, Houston, Texas (paper SPE 106402)

Wu Y, Shuler P J, Blanco M, et al. An experimental study of wetting behavior and surfactant EOR in carbonates with model compounds. SPE Journal. 2008. 13(1): 26-34 (paper SPE 99612)

Xie Q, He S L and Pu W F. The effects of temperature and acid number of crude oil on the wettability of acid volcanic reservoir rock from the Hailar Oilfield. Petroleum Science. 2010. 7(1): 93-99

Xie X, Weiss W W, Tong Z, et al. Improved oil recovery from carbonate reservoirs by chemical stimulation. SPE Journal. 2005. 10(3): 276285 (paper SPE 89424)

Xu W, Ayirala S C and Rao D N. Wettability alterations due to crude oil composition and an anionic surfactant in petroleum reservoirs. Journal of Adhesion Science and Technology. 2006. 20(7): 693-704

Xu W, Ayirala S C and Rao D N. Measurement of surfactant-induced interfacial interactions at reservoir conditions. SPE Reservoir Evaluation \& Engineering. 2008. 11(1): 83-94 (paper SPE 96021)

Yan J N. Influence of synergistic action of brine and asphaltenes on reservoir wettability. Drilling Fluid and Completion Fluid. 1998a. 15(1): 3-7 (in Chinese)

Yan J N. The adsorption characteristics of crude oil asphaltenes on reservoir rock surfaces. Petroleum Exploration and Development. 1998b. 25(2): 78-82 (in Chinese)

Yao T Y and Li J S. Interaction between cationic surfactants and acids in crude oil and wettability alternation. Journal of Central South University (Science and Technology). 2009. 40(1): 83-87 (in Chinese)

Yu L and Wardlaw C. The influence of wettability and critical porethroat size ratio on snap-off. Journal of Colloid and Interface Science. 1986. 109(2): 461-472

Zhang L, Wang Z, Li Z, et al. Wettability of a quartz surface in the presence of four cationic surfactants. Langmuir. 2010. 26(24): 18834-18840

Zhang L D, Liu S, Puerto M, et al. Wettability alteration and spontaneous imbibition in oil-wet carbonate formations. Journal of Petroleum Science and Engineering. 2006. 52(1-4): 213-226

Zhang P, Tweheyo M T and Austad T. Wettability alteration and improved oil recovery by spontaneous imbibition of seawater into chalk: Impact of the potential determining ions $\mathrm{Ca}^{2+}, \mathrm{Mg}^{2+}$, and $\mathrm{SO}_{4}{ }^{2-}$. Colloids and Surfaces A: Physicochemical and Engineering Aspects. 2007. 301(1-3): 199-208

Zhou X, Morrow N R and Ma S. Interrelationship of wettability, initial water saturation, aging time, and oil recovery by spontaneous imbibition and waterflooding. SPE Journal. 2000. 5(2): 199-207 (paper SPE 62507) 